\title{
Fire Resistance Analysis of Prestressed Steel Structure Based on the Study of High Temperature Mechanical Properties of Steel Strands
}

\author{
Junhui HOU ${ }^{\mathrm{a}}$, Hongming LI $^{\mathrm{a}, 1}$, Dan XIE ${ }^{\mathrm{a}}$, Lulu QIAN ${ }^{\mathrm{a}}$ and Baijian TANG ${ }^{\mathrm{a}, \mathrm{b}}$ \\ ${ }^{a}$ Jiangsu University of Science and Technology, School of Architecture and Civil \\ Engineering, China \\ ${ }^{\mathrm{b}}$ Suzhou University of Science and Technology, Civil engineering College, China
}

\begin{abstract}
On the basis of the existing test data of high temperature mechanical properties of 1860 grade steel strands, a regression model of high temperature performance of steel strands that can be used for theoretical analysis and numerical calculation is obtained. Based on the non-stationary temperature field model in the fire of tall and large space buildings, the non-linear finite element numerical analysis method considering the time integral effect is used to establish the fire resistance numerical model of the large-span prestressed steel structure. Through the fireresistance calculation example of Beam String Structure, the influence of different fire source positions on the fire-resistance of prestressed steel structures is discussed.
\end{abstract}

Keywords. Steel stranded wire, high temperature mechanical properties, beam string structure, finite element numerical analysis, fire-resistant engineering.

\section{Introduction}

Prestressed steel structure is favored by architects due to its light weight, high stability and superior force performance, and is widely used in large-span space buildings. However, the disadvantage of steel structure is its poor fire resistance. In a high temperature environment, the steel's elastic modulus, yield strength and other mechanical indicators will change dramatically, resulting in the overall bearing capacity and internal force of the structure being different from normal temperature. Therefore, it is very necessary to conduct fire resistance analysis. Sun Hao[1] obtained the loss of prestress of the steel column under fire conditions through the thermal-mechanical coupling analysis of the prestressed steel column. Zhou Huanting[2] conducted a high-temperature experimental study on prestressed axial tension steel members, and obtained the full time history curve of the tension of the prestressed axial tension rod and the axial displacement of the prestressed steel rod under high temperature. Nie Hebin[3] deduced the tension degeneration law of the prestressed axial compression strut steel column under the whole fire process and the calculation formula of axial deformation. Du Yong[4] carried out the

${ }^{1}$ Corresponding Author, Hongming LI, Jiangsu University of Science and Technology, School of Architecture and Civil Engineering, China; E-mail: 20156436@qq.com. 
high temperature mechanical performance test of cold drawn 1860 grade steel strand and established the function model of the high temperature reduction coefficient of the mechanical performance index of the steel strand. Fan Jin[5] obtained the change law of the ultimate strength, yield strength, and elastic modulus of the steel strand with temperature through the mechanical performance test of the prestressed steel strand specimens at different temperatures. Zhou Huanting and Li Guoqiang[6] conducted tensile tests on steel stranded wire bundles at high temperatures, and obtained the stressstrain relationship curve, yield strength, tensile strength, and the relationship between elastic modulus and temperature at the corresponding temperature. They built a hightemperature performance model of steel strands on the basis of test data.

The author summarized and analyzed the high-temperature mechanical performance test data of steel strands in the literature [4], [5], [6], and regressed the high-temperature performance model of steel strands that can be used for theoretical analysis and numerical calculation. The author combines the non-stationary temperature field model in the fire of tall and large space buildings, and through the example of beam string, discusses the influence of different fire source positions on the fire resistance of prestressed steel structures.

\section{Analysis of Steel Performance Parameters at High Temperature}

The mechanical properties of steel will change significantly in a high temperature environment, and the key indicators such as the elastic modulus and yield strength of steel will decrease significantly with the increase of temperature. This article refers to the relevant index reduction coefficients given in the European norm EC3[7] for value, and will not be repeated here.

Stranded wire is different from ordinary steel in terms of production process and structure, and its mechanical properties at high temperatures are still quite different from ordinary structural steel. In order to understand the mechanical properties of steel strands at high temperatures, many domestic scholars have conducted high-temperature mechanical performance tests on 1860 grade steel strand commonly used in engineering.

Literature [4] uses a constant temperature loading mode and uses a non-contact strain video measurement system to monitor 36 specimens at 13 temperature points. Literature [5] also used the constant temperature loading mode, and tested the mechanical properties of 1860 grade steel strands at 12 temperature points between $20^{\circ} \mathrm{C} \sim 600^{\circ} \mathrm{C}$. Literature [6] also adopted the constant temperature loading mode, and conducted mechanical performance tests on 27 specimens at 9 temperature points $20^{\circ} \mathrm{C}$, $100^{\circ} \mathrm{C}, 200^{\circ} \mathrm{C}, 300^{\circ} \mathrm{C}, 400^{\circ} \mathrm{C}, 500^{\circ} \mathrm{C}, 550^{\circ} \mathrm{C}, 600^{\circ} \mathrm{C}$ and $700^{\circ} \mathrm{C}$.

The experimental data comparison of literature [4], [5], [6] is shown in figure 1. It can be seen from the comparison chart that there are obvious differences in the data obtained using the same test method:

In terms of elastic modulus, there is a sudden change in the data value of literature [5] in $20^{\circ} \mathrm{C} \sim 150^{\circ} \mathrm{C}$, the elastic modulus reduction coefficient drops rapidly, and then it rises back. In literature [4] and literature [6], in the interval $20^{\circ} \mathrm{C} \sim 600^{\circ} \mathrm{C}$, the data trend and value are very similar, but if it exceeds $600^{\circ} \mathrm{C}$, the curve change of literature [4] tends to be flat, while the curve trend of literature [6] remains unchanged. 
In terms of yield strength, When the temperature exceeds $400^{\circ} \mathrm{C}$, the decline in literature [4] and [5] is obvious, and when the temperature exceeds $600^{\circ} \mathrm{C}$, the curve change trend of literature [4] is more gradual. The curve of literature [6] is generally above that of literature [4] and [5], and the measured yield strength at the same temperature is larger than the other two.
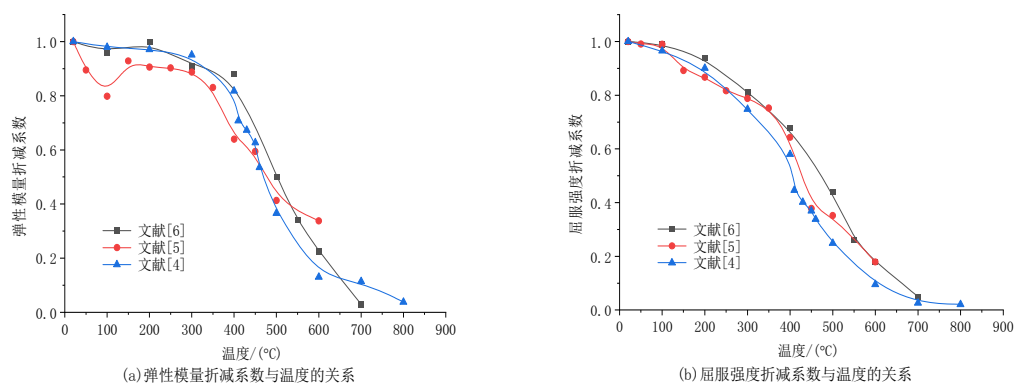

Figure 1. High temperature mechanical performance test results of steel strand

In summary, the author comprehensively averaged the 3 sets of data, and perform regression analysis on the processed data. Finally, the relationship expressions of the yield strength reduction coefficient and elastic modulus reduction coefficient of steel strands with temperature change are obtained.

Modulus of elasticity reduction factor:

$$
E_{T}=-3.07275 \times 10^{-14} T^{5}+7.74759 \times 10^{-11} T^{4}-6.42338 \times 10^{-8} T^{3}+1.88426 \times 10^{-5} T^{2}-0.0023 T+1.04251
$$

Yield strength reduction factor:

$$
f_{y T}=-1.08273 \times 10^{-14} T^{5}+2.58374 \times 10^{-11} T^{4}-1.80901 \times 10^{-8} T^{3}+2.53812 \times 10^{-6} T^{2}-4.81618 \times 10^{-4} T+1.0115
$$

The degree of agreement between the expressions (1) and (2) and the test data is shown in figure 2. It can be seen from the figure that the processed test data agrees well with the regression expression.
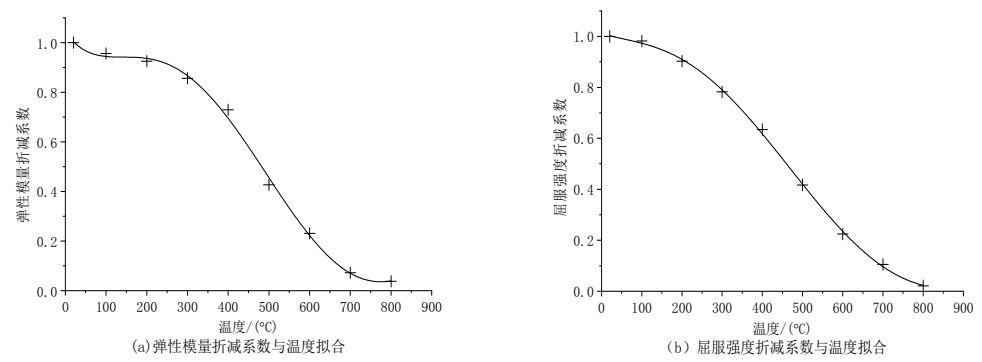

Figure 2. Regression results of test data 


\section{Fire Temperature Field}

When a fire occurs, combustible materials ignite to form a heat source, and the heat is first released into the surrounding air, causing the air temperature to continue to rise. This article considers factors such as fire source power, building height, fire source distance, etc., and adopts the empirical formula of fire air heating in large space buildings proposed by Li Guoqiang[8].The formula expression is as follows:

$$
T(x, z, t)=T_{g}(0)+T_{z}[1-0.8 \exp (-\beta t)-0.2 \exp (-0.1 \beta t)] \times\left[\eta+(1-\eta) \exp \left(-\frac{x-b}{\mu}\right)\right]
$$

Steel components are divided into two types: with protective layer and without protective layer. This paper only considers the case of no protective layer, and calculates the temperature rise of steel components in accordance with the incremental method in the "Technical Code for Fire Protection of Building Steel Structures" CECS200-2006 [9].

The formula expression is as follows:

$$
\begin{gathered}
\Delta T_{s}=\frac{\Delta t}{\rho_{s} C_{s}} \times \frac{F}{V} \times\left\{\varepsilon_{r} \sigma\left[\left(T_{g}+273\right)^{4}-\left(T_{s}+273\right)^{4}\right]+\varepsilon_{c}\left(T_{g}-T_{s}\right)\right\} \\
T_{s}^{j+1}=T_{s}^{j}+\Delta T_{s}
\end{gathered}
$$

\section{Analysis of Calculation Examples of Fire Resistance of Prestressed Steel Members}

Take the prestressed string beam structure as an example (figure 3). One end of the component is fixed with a support, and the other end is a sliding hinge support (which can move in the horizontal direction). The upper chord arch beam is made of rectangular steel pipe $(300 \mathrm{~mm} \times 200 \mathrm{~mm} \times 20 \mathrm{~mm})$, and the lower chord prestressed cable is made of grade 1860 steel strand $\left(7 \phi^{j} 15.2\right)$. The middle brace is made of hollow thin-walled steel pipe (outer diameter $30 \mathrm{~mm}$, wall thickness $10 \mathrm{~mm}$ ). The yield strength of rectangular steel pipes and thin-walled steel pipes is $235 \mathrm{MPa}$ at room temperature, and the elastic modulus is $2.1 \times 105 \mathrm{MPa}$. The elastic modulus of the steel strand at room temperature is $1.95 \times 105 \mathrm{MPa}$.

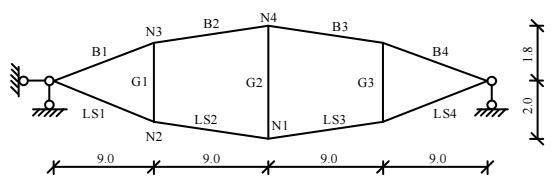

Figure 3. String beam structure

\subsection{Temperature Field and Mechanical Properties of Components}

The fire source used in this paper is $25 \mathrm{MW}$, a medium-speed growth type, the fire duration is 2 hours, and the building area is $500 \mathrm{~m}^{2}$. The highest point of the string beam member is at a vertical distance of $12 \mathrm{~m}$ from the center of the fire source, and the fire 
source is arranged under the side span and the middle span of the string beam respectively. The air temperature and component temperature are calculated according to equations (3) and (4), and the results are shown in figure 4. The mechanical properties of the string beam at high temperature are calculated according to formula (1) and (2).
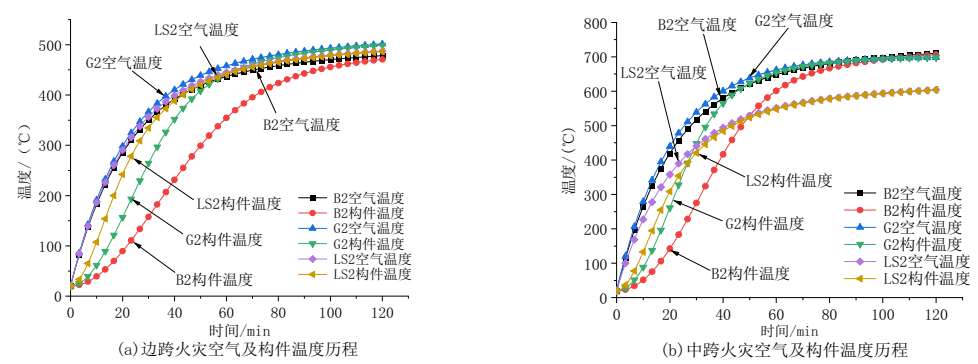

Figure 4. Component temperature and air temperature-time relationship curve

\subsection{Result Analysis}

The left side of figure 5 is the calculation result of the horizontal displacement of the right end support of the string beam structure. It can be seen from the figure that the structure exhibits nonlinear changes under high temperature. During the fire process, the horizontal displacement of the bearing caused by the mid-span fire was always greater than that of the side-span fire, and the maximum difference between the two reached $73 \mathrm{~mm}$. As the temperature rises, the change trend of the mid-span fire bearing displacement is obviously faster than that of the side span. The figure clearly shows the influence of the fire source position on the structural deformation.
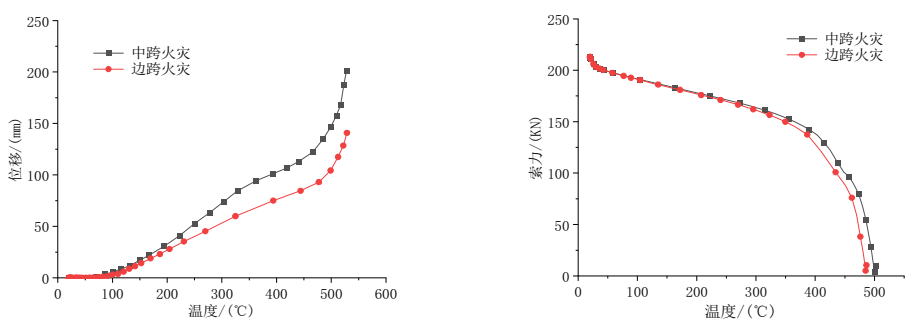

Figure 5. The relationship curve of displacement, cable force and temperature

The right side of figure 5 is the calculation result of the internal force of the lower cable of the string beam. It can be seen from the figure that as the temperature rises, the internal force of the prestressed cable continuously decreases and shows a non-linear change. When the temperature is $200^{\circ} \mathrm{C}$, the cable force loss caused by the side span fire is $16.9 \%$, and the cable force loss caused by the mid-span fire is $15.9 \%$. As the temperature rises to $450{ }^{\circ} \mathrm{C}$, the side span fire cable power loss increases to $58.6 \%$, and the mid-span fire cable power loss reaches $52.6 \%$. It can be seen that the fire sources at different positions have little effect on the degree of change of the internal force of the cable, and the change curves are very similar. 


\section{Conclusions}

(1) The regressed steel strand elastic modulus and yield strength reduction coefficient expressions can be better used in the fire resistance analysis of prestressed steel structures. (2) During the entire heating process, the beam string structure exhibits very significant nonlinear mechanical characteristics, and the internal force of the prestressed cable has been in a decreasing state. The high temperature makes the cross-section geometric stiffness of the steel member decrease, causing the structure to deform. The higher the temperature, the greater the degree of deformation until the structure becomes unstable.

(3) The location of the fire source makes the temperature unevenly distributed in the steel components, resulting in a temperature difference, causing additional stress, and redistributing the overall structural stress. The location of the fire source has a nonnegligible impact on the mechanical response of the prestressed steel structure at high temperatures, and it must be determined first in the fire-resistant engineering.

\section{References}

[1] Sun Hao, Zhu Jiang, Sun Qiang. Analysis of prestress loss of prestressed steel column under fire environment[J]. Journal of Lanzhou Institute of Technology, 2017, 024(005): 31-35.

[2] Zhou Huanting, Zhang Jian, Nie Hebin, Li Guoqiang. High temperature performance test and theoretical study of prestressed axial tension steel members[J]. Journal of Building Structures, 2016, 37(02): 114122.

[3] Nie Hebin. Research on fire resistance performance of prestressed axial compression strut steel column[D]. Wuhan University of Technology, 2015.

[4] Du Yong, Sun Yakai, Li Guoqiang. Experimental study on high temperature mechanical properties of prestressed steel strands[J]. Engineering Mechanics, 2019, 36(04): 231-238.

[5] Fan Jin, Lv Zhitao. Experimental study on the performance of prestressed steel strands under high temperature[J]. Building Structure, 2002(03): 50-63.

[6] Zhou Huanting, Li Guoqiang, Jiang Shouchao. Experimental study on the mechanical properties of steel strand materials at high temperature[J]. Journal of Sichuan University (Engineering Science Edition), 2008(05): 106-110.

[7] Eurocode3-Design of Steel structures[S], Part1-2: Structural Fire Design. European Committee for Standardization, 2002.

[8] Li Guoqiang, Du Yong. Practical empirical formula for fire air heating in large space buildings[J]. Fire Science and Technology, 2005(03):283-287.

[9] CECS200:2006, Technical Code for Fire Protection of Building Steel Structures [S]. 